\title{
DOENÇA DE KRABBE \\ (LEUCODISTROFIA A CÉLULAS GLOBÓIDES)
}

\author{
A PROPÓSITO DE CINCO OBSERVAÇÕES
}

S. ROSEMBERG - S. E. KLIEMANN - F. N. ARITA

RESUMO - Foi realizado estudo clínico de 5 observações da doença de Krabbe (leueodistrofia a células globóides). O' diagnóstico de certeza, seja pelo estudo neuropatológico pós mortem ( 2 casos), seja pela dosagem enzimática em fibroblastos em cultura ( 2 casos), foi alcançado em 4 observações. A biópsia de nervo periférico foi realizada nos 5 casos e o estudo ultrastrutural revelou, em todos, aliterações características da doença de Krabbe. Os autores chamiam a atenção para os principais dados clínicos e laboratoriais que sugerem o diagnóstico da doença, mesmo na impossibilidade da realização de exame ultrastrutural de nervo periférico e das dosagens enzimáticas, estas não realizadas em nosso país.

PALAVRAS-CHAVE: doença de Krabbe, leucodistrofia, células globóides, encefalopatías metabólicas.

Krabbe's disease (globoid cell leukodystrophy): a report of five cases.

SUMMARY - A clinical study on five cases of Krabbe's disease (globoid cell leukodistrophy) was performed. A final diagnosis was done either with post-mortem study (two cases) or by enzymatic assays carried on cultured fibroblasts (two cases). Peripheral nerve biopsy for electron microscopy was performed in all cases, and the ultrastructural alterations characteristics of Krabbe's disease were always found. The authors emphasize the suggestive clinical and laboratory data which enable the diagnosis of Krabbe's disease in the absence of the ultrastructural exam of peripheral nerve, or the enzymatic assays not performed in this country.

KEY WORDS: Krabbe's disease, leukodystrophy, globoid cells, metabolic encephalopathies.

A doença de Krabbe, ou leucodistrofia a células globóides, é entidade genética que se transmite segundo o modo autossômico recessivo e se deve a deficiência da enzima lisosomial galactocerebrosídeo /?-galactosidade i*. Em consequência, há acúmulo cerebral de galactocerebrosídeo e de psicosina. O aparecimento desta última levaría a destruição dos oligodendrocitos, o que resulta numa desmielinização maciça no sistema nervoso central 7. A bainha de mielina do sistema nervoso periférico também é comprometida. O acúmulo de galactocerebrosídeo elicita a formação das células globóides, que parecem ser macrófagos carregados desta substância e são patognomônicas da doença ${ }^{2}$. Nas células de Schwann e em células mesenquimais do nervo periférico, o galactocerebrosídeo forma estruturas lamelares cristaliformes características, cuja visualização à microscopia eletrônica é de importante valor diagnóstico ${ }^{11}$. Há diferentes formas clínicas da doença. De longe, a mais frequente é a forma infantil precoce que se inicia no

Trabalho reaflizado no Departamento de Pediatria (Disciplina de Neuropediatria) da Faculdade de Medicina da Santa Casa de São Paulo e no Departamento de Patologia (Disciplina de Neuropatologia) da Faculdade de Medicina da Universidade de São Paulo (USP).

Dr. Sérgio Rosemberg - Departamento de Patologia, Faculdade de Medicina, USP - Av. Dr. Arnaldo 455 - 01246 São Paulo SP - Brasil. 
primeiro ano de vida, geralmente após os 3 meses de idade. Forma infantil tardia, com início de 2 a 6 anos, e forma juvenil, com início após os 6 anos, foram descritas, porém permanecem excepcionais io,i3. O diagnóstico de certeza é feito pela dosagem de galactocerebrosídeo /3-galactosidase em fibroblastos em cultura e em leucócitos Este é um procedimento complexo não realizado em nosso meio e, mesmo no exterior, apenas alguns laboratórios de referência estão capacitados a realizá-lo. Assim sendo, o diagnóstico é feito pelo quadro clínico, que é bastante sugestivo, e por exames laboratoriais, como dosagem de proteínas no líquido cefalorraqueano (LCR) e realização de eletromiografia (EMG), devendo ser complementado com o exame ultrastrutural de nervo periférico que, se positivo, selará praticamente o diagnóstico, podendo-se então prescindir da dosagem enzimática.

A fim de bem salientar as principais características clínicas e laboratoriais que permitem o diagnóstico desta rara, porém não excepcional, doença neurológica, relatamos nossa experiência com 5 casos da doença de Krabbe, forma infantil precoce.

\section{CASUÍSTICA}

Observação 1 - RLiM, sexo masculino, pais sadios, primos em lo grau. Tem um irmão de 6 anos saudável e outro que faleceu com 13 horas de vida por causa desconhecida. Evoluiu normalmente ate" o 29 mês de vida, quando se iniciaram espasmos caracterizados por hiperextensão dos membros e cabeça, choro e irritabilidade constantes, e surtos febris inexpSicados. Aos 3 meses, foi internado em outro hospital quando, diante da complexibilidade do quadro, foi transferido para nosso Serviço onde deu entrada aos 4 meses de idade. O exame neurológico mostrou criança consciente, com contacto precário, limitando-se a seguir com o olhar de modo fugaz, extremamente irritada à manipulação que provocava hiperextensão dos membros e da cabeça (Fig. 1). A movimentação espontânea era pobre, havia certa hipotonia axial quando relaxada e hipertonia apendicular. Os reflexos profundos achavam-se abolidos nos 4 membros, sinais de Rossolimo e de Babinski presentes. Ausência de movimentos involuntários anormais com exceção dos espasmos. Nervos cranianos normais. PC $41 \mathrm{~cm}$. A criança permaneceu internada por 2 meses. Durante este período houve deterioração do estado neurológico, tendo o contato se tornado mais precário, os espasmos e a postura em opistótono praticamente permanentes. Os exames complementares realizados incluíram hemograma, ionograma, gasometria, ferro sérico, eletroforese de hemoglobina, G6PD, com resultados normais. Os exames do LCR mostraram sempre valores normais de células, cloretos e glicose, c teores elevados de proteína que variaram entre 65 e $182 \mathrm{mg} / \mathrm{dL}$, com perfil eletroforético normal. O exame fundoscópico revelou-se normal, o mesmo ocorrendo com o eletrencefalograma (EEG).

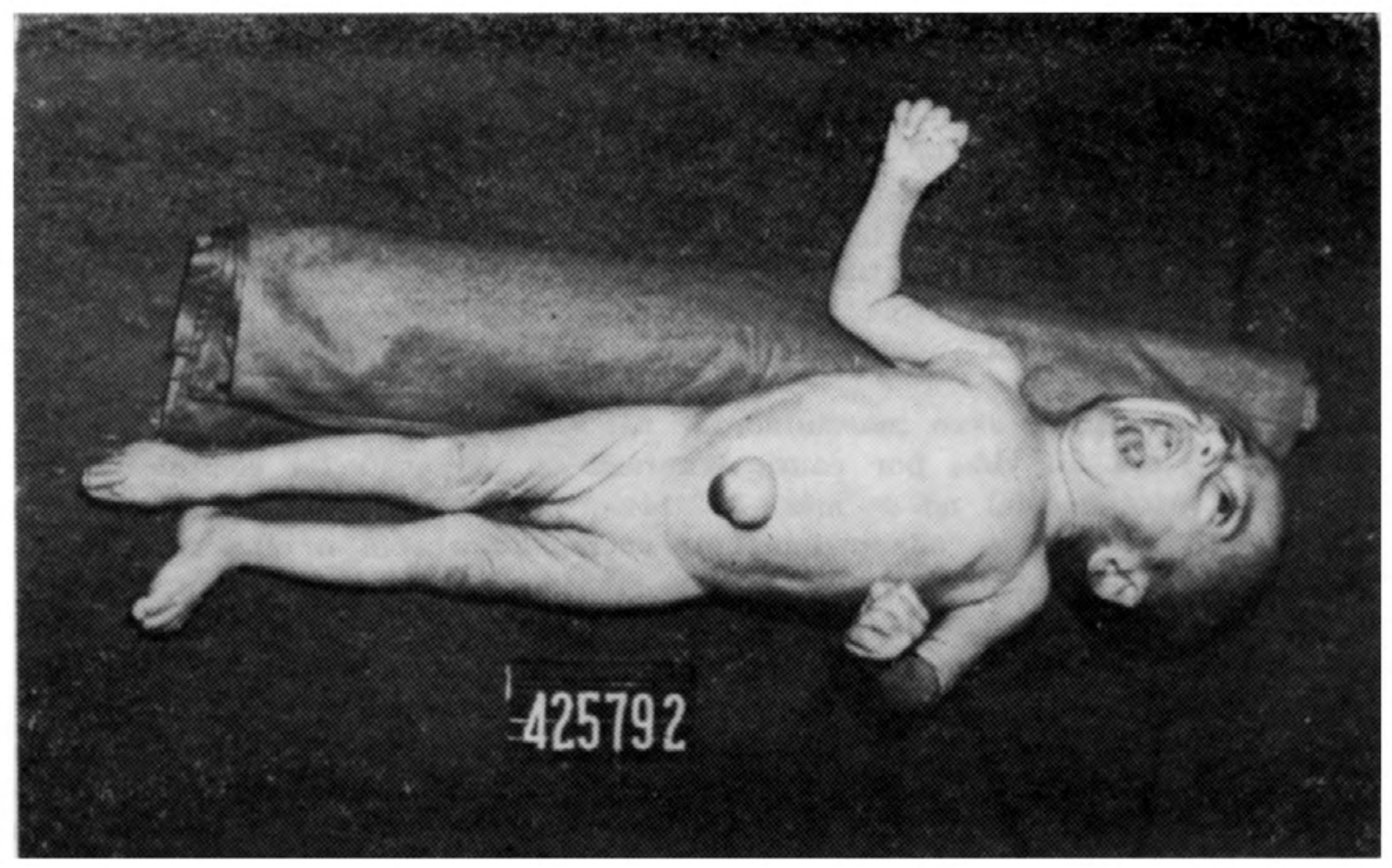

Fig. 1. Obs. 1. Posição em extensão de membros e cabeça, sugestiva da doença de Krabbe. 
Tomografia computadorizada de crânio (CT) mostrou discreta atrofia cerebral difusa. A biópsia de nervo periférico revelou inclusões sehwanianas cristaliformes. EMG mostrou velocidade de condução sensitiva e motora abolidas. A criança foi internada novamente, 3 meses após, em mau estado geral, febril, septicêmica, com meningite purulenta, ocorrendo o óbito 6 dias após, com a idade de 9 meses. O exame neeroscópico revelou leucodistrofia a células globóides.

Observação 2 - CMS, sexo feminino, filha de pais não consanguíneos. Teve um irmão que faleceu aos 13 meses após doença neurológica semelhante à da paciente e outro de 6 anos, normal. Evoluiu normalmente até os 6 meses de idade quando, por ocasião de quadro gripal, os país notaram que estava miais «molinha», já não se sentava com bom equilíbrio, não mais apanhava os objetos com desenvoltura e passou a se desinteressar progressivamente pelo meio. Muitas vezes, quando segurada no colo, hiavia enrijecimento dos membros extensão da cabeça para trás. Este quadro piorou progressivamente e a família procurou nosso Serviço. À entrada, tratava-se de criança consciente, fixando e seguindo os objetos com o olhar e parecendo se interessar pelo meio. Muito irritada à manipulação. A mobilidade espontânea era pobre, não sentava com ou sem apoio, não manipulam objetos. Permanecia no leito em decúbito obrigatório, com tendência a hiperextensão dos membros e da cabeça. Os reflexos profundos eram hiperativos nos 4 membros. Clono esgotável dos pés e sinais de Babinski e de Rossolimo presentes. Nervos cranianos normais, PC 41 2/3cm. Os exames de rotina, bem como gasometría e ionograma, reveCaram-se normais. O exame fundoscópico foi normal e o exame do LtCR revelou $160 \mathrm{mg} / \mathrm{dL}$ de proteínas, 689mg/dLi de cloretos, 20mg/dL de glicose e 3 leueócitos/mm3. A CT do crânio revelou discreta hipoatenuação de substância branca ao redor do trígono ventricular. O exame ultrastrutural de nervo periférico revelou inclusões cristaliformes nas células de Schwann. A dosagem enzimática em fibroblastos mostrou taxas não detectáveis de galactocerebrosídeo ^g-galaetosidase. A criança foi acompanhada em ambulatório até a idade de 2 a $8 \mathrm{~m}$, tendo-se assistido o aparecimento de crises convulsivas tipo grande mal a partir do 13<? mês, que nunca puderam ser bem controladas, e deterioração psicomotora completa, tendo a criança entrado a partir dos 2 anos num estado vegetativo.

Observação 3 - BVM, sexo feminino, filha única de pais não consanguíneos. Evoluiu bem até os 4 meses apesar de a mãe ter referido que nunca sustentou perfeitamente a cabeça. Nesta época, tendo-se notado discreto atraso motor, a criança foi submetida a fisioterapia. A partir dos 6 meses percebeu-se piora do quadro, tendo a criança gradativamente deixado de acompanhar com o olhar, de se interessar e apanhar objetos. Aos 7 meses passou a apresentar episódios de endurecimento do corpo e membros, com hiperextensão de cabeça, sem perda da consciência. Com 10-11 meses, notou-se dificuldade para mamar, salivação intensa, aumento dos episódios de espasmos e irritabilidade freqüiente. Com 14 meses deu entrada em nosso Serviço para diagnóstico. O exame neurológico mostrou criança sem nenhum contacto com meio, não se defendendo ao exame, em decúbito' dorsal obrigatório e motilidade espontânea praticamente nula, sem apoio plantar. Havia acentuada hipotonia global. Os reflexos profundos estavam abolidos e obtinham-se os sinais de Rossolimo e de Babinski bilateralmente. Ausência de movimentos involuntários anormais, com exceção de clonias globais importantes eii citad as por estímulos sonoros. Nervos cranianos sem alterações. PC44cm. A fundoscopia revelou-se normal. Os exames laboratoriais de rotina foram normais. LCR mostrou 0 células $/ \mathrm{mm} 353 \mathrm{mg} / \mathrm{dL}$ de proteína, $53 \mathrm{mg} / \mathrm{dLi}$ de glicose e $735 \mathrm{mg} / \mathrm{dL} \gg$ de cloretos. O BEG mostrou ondas lentas com caráter contínuo ao lado de ondas agudas de projeção difusa. O EMG mostrou comprometimento grave, do tipo desmielinizante (velocidades de condução sensitiva não obtidas). A biópsia de nervo periférico revelou inclusões cristaliformes nas células de Schwann. Dosagem enzimática em fibroblastos revelou déficit de galactocerebrosídeo $\wedge$-ga lactosidase $(0,08$ microkat/kg proteína; normal $0,86 \pm 0,49)$. A criança faleceu em hospital de outra cidade aos $16 \mathrm{~m}$. Não foi realizada autópsia.

Observação 4 - RSM, sexo masculino, 2» filho de pais não consanguíneos. O primeiro filho faleceu no 6 ? dia de vida por causa ignorada. A gestação foi complicada, a mãe fez cerclagem. O parto foi normal no 6? mês. PN 1440g. Permaneceu no berçário 45 dias e teve alta com l\&üOg. Desenvolveu-se adequadamente: acompanhou com o oflhar com 3 m, sustentou a cabeça com $5 \mathrm{~m}$, apanhou objetos com $6 \mathrm{~m}$, sentou com apoio aos $7 \mathrm{~m}$ e, aos $9 \mathrm{~m}$, ficou em pé com apoio. Nesta idade a mãe notou que tendia a enrijecer o tronco para trás, quando segurada, passando a sentar com menos equilíbrio, caindo para os lados. Com ICm, as mãos permaneciam fechadas quase todo o tempo e começou a emagrecer e a apresentar hipertonia dos membros inferiores. Após várias passagens por outros serviços, deu entrada na Santa Casa aos 15 meses. O exame neurológico revelou criança com extrema irritabilidade à manipulação, permanecendo no leito em decúbito dorsal obrigatório, com hipertonia em hiperextensão dos 4 membros. Contato precário, limitado ao seguimento com o olhar. Os reflexos profundos estavam abolidos nos 4 membros, Sinais de Babinski e de Rossolimo presentes bi- 
lateralmente. Nervos cranianos normais. PC $43,5 \mathrm{~cm}$. Os exames laboratoriais de rotina não mostraram alterações. O exame do LCR mostrou 3 leucócitos/mm3, 102mg/dL de proteína, $718 \mathrm{mg} / \mathrm{dD}$ de cloretos e $57 \mathrm{mg} / \mathrm{dL}$ de glicose. O EEG revelou raras ondas agudas de projeção difusa. CT do crânio mostrou discreta atrofia cortical e o exame de ressonância nuclear magnética (RNM) revelou moderada atrofia difusa, hipo sinal em Tl e hiper sinal em T2 de substância branca periventricular (Fig. 2). A injeção* de Gadolineo-DTPA evidenciou realces subcorticais. A biópsia do nervo sural mostrou inclusões cristaüiformes no citoplasma tias células de Schwann (Fig. 3).

Observação 5 - LC, sexo masculino, primeiro filho* de pais primos em primeiro grau. Parto cesariano no 7 « mês de gestação' por amniorexis. PN 1500g. Permaneceu em berçário por 25 dias e teve alta com 1900g. Evoluiu normalmente, tendo seguido com o olhar aos 2 meses, sorriso social e sustentação da cabeça com 3 meses, ccmeçou a sentar com apoio aos 5 meses. Nesta idade, a mãe percebeu que a criança foi ficando menos ativa, sorrindo menos, sentando-se com mais dificuldade e não tendo bom apoio plantar. Passou a apresentar episódios de hiperextensão de cabeça e membros, bem como choro intenso. Deu entrada em nosso Serviço aos $8 \mathrm{~m}$, consciente, com motilidade pobre, praticamente nula, muito chorosa e irritada à manipulação. Havia hipotonia axial e hipertonia apendicular. Permanecia em decúbito dorsal obrigatório, com tendência a hiperextensão dos membros. Reflexos profundos universalmente abolidos, com evidentes sinais de liberação piramidal, com sinais de Rossolimo e de Babinski bilaterais e clono dos pés. Nervos cranianos normais. PC $42,5 \mathrm{~cm}$. F.O. normal. Exames laboratoriais de rotina normais. LCR: 4 leucócitos/mm3, 144mg/dL de proteínas, $724 \mathrm{mg} / \mathrm{dL}$ de cloretos e $24 \mathrm{mg} / \mathrm{dL}$ de glicose; eletroforese de proteínas normal. O EEG mostrou freqüentes ondas agudas e pontas em áreas fronto-centrais, ora a esquerda, ora à direita, de modo independente. O EMG mostrou alterações compatíveis a lesão do sistema

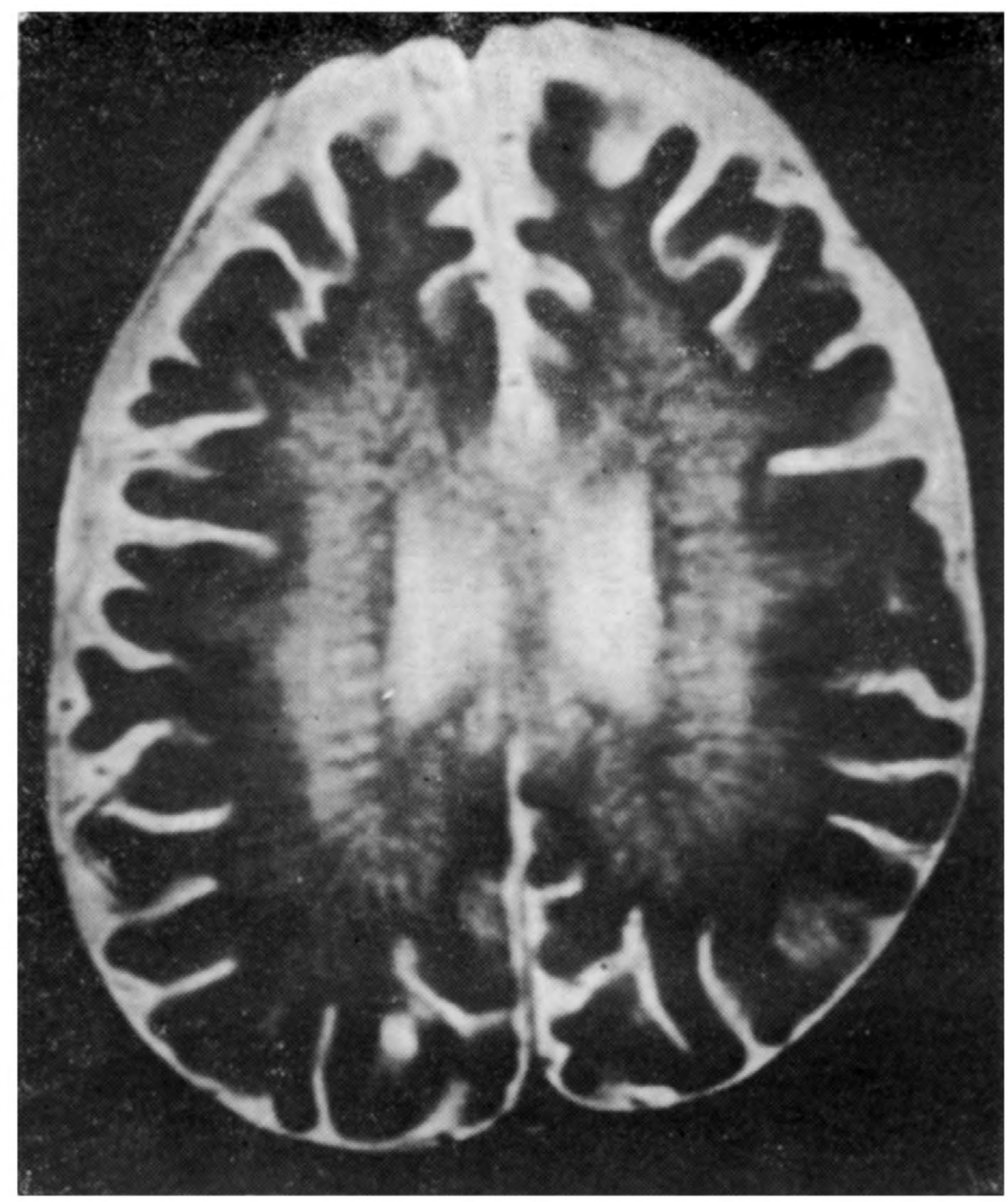

Fig. 2. Obs. 4. RNM mostrando hiper sinal da substancia branca periventricular em T2. A CT de cranio havia sido normal. 
Tabela 1. Doença de Krabbe: características principais dos 5 pacientes estudados.

\begin{tabular}{|c|c|c|c|c|c|c|c|c|c|c|c|}
\hline No & $\begin{array}{l}\text { Sexo/ } \\
\text { Idade }\end{array}$ & $\begin{array}{l}\text { Idade } \\
\text { de } \\
\text { inficio }\end{array}$ & $\begin{array}{l}\text { Primeiros } \\
\text { sinais e } \\
\text { sintomas }\end{array}$ & Exame neurolúgico & $\begin{array}{l}\text { História } \\
\text { familiar }\end{array}$ & LCR & EMG & CT/RNM & $\begin{array}{l}\text { Biopsia } \\
\text { nervo }\end{array}$ & $\begin{array}{l}\text { Estudo } \\
\text { enzimá- } \\
\text { tico * }\end{array}$ & Evolução \\
\hline 1 & $\mathrm{M} / \mathbf{4 m}$ & $2 \mathrm{~m}$ & $\begin{array}{l}\text { Espasmos, } \\
\text { irritabilidade } \\
\text { hipertonia, } \\
\text { surtos de } \\
\text { febre }\end{array}$ & $\begin{array}{l}\text { Segue com o olhar, } \\
\text { hipertonia global, } \\
\text { reflexos profundos } \\
\text { abolidos, Babinski e } \\
\text { Rossolimo PC } 41 \mathrm{~cm}\end{array}$ & $\begin{array}{l}\text { Pais primos } \\
\text { 10 grau }\end{array}$ & $\begin{array}{l}144 \mathrm{mg} / \mathrm{dL} \\
\text { proteina }\end{array}$ & $\begin{array}{l}\text { Diminuição } \\
\text { da velocidade } \\
\text { de condução } \\
\text { sensitiva e } \\
\text { motora }\end{array}$ & $\begin{array}{l}\text { CT: Atrofia } \\
\text { cortical } \\
\text { difusa }\end{array}$ & + & & $\begin{array}{l}\text { obito aos } 15 \mathrm{~m} \\
\text { Autópsia: } \\
\text { leucodistrotia } \\
\text { a células } \\
\text { globóides }\end{array}$ \\
\hline 2 & $\mathrm{~F} / 8 \mathrm{~m}$ & $6 m$ & $\begin{array}{l}\text { Apatia, } \\
\text { recusa } \\
\text { manipulação, } \\
\text { espasmos, } \\
\text { tendência a } \\
\text { opistótono }\end{array}$ & $\begin{array}{l}\text { Segue com o olhar, } \\
\text { irritabilidade, hiper- } \\
\text { tonia, opistótono, } \\
\text { reflexos profundos } \\
\text { hipoativos, clono dos } \\
\text { pés, PC } 41 / 2 / 3 \mathrm{~cm}\end{array}$ & $\begin{array}{l}\text { Um irmão } \\
\text { faleceu } \\
\text { após doença } \\
\text { semelhante }\end{array}$ & $\begin{array}{l}160 \mathrm{mg} / \mathrm{dL} \\
\text { proteína }\end{array}$ & $\begin{array}{l}\text { Diminuição } \\
\text { da velocidade } \\
\text { de condução } \\
\text { sensitiva e } \\
\text { motora }\end{array}$ & $\begin{array}{l}\text { CT: Hipoden- } \\
\text { sidade peri- } \\
\text { ventricular }\end{array}$ & + & + & $\begin{array}{l}\text { Crises convul- } \\
\text { sivas a partir } \\
\text { de } 14 \text { meses; } \\
\text { perda de } \\
\text { seguimento } \\
\text { aos } 2 \text { anos }\end{array}$ \\
\hline 3 & $\mathrm{~F} / 13 \mathrm{~m}$ & $4 m$ & $\begin{array}{l}\text { Cessou de } \\
\text { sorrir, } \\
\text { dificuldade } \\
\text { para firmar a } \\
\text { cabeça e } \\
\text { sentar }\end{array}$ & $\begin{array}{l}\text { Sem contato, irrita- } \\
\text { bilidade, hipertonia, } \\
\text { reflexos profundos } \\
\text { abolidos, Rossolimo } \\
\text { e Babinski, PC } 44 \mathrm{~cm}\end{array}$ & - & $\begin{array}{l}69 \mathrm{mg} / \mathrm{dL} \\
\text { proteína }\end{array}$ & $\begin{array}{l}\text { Diminuição } \\
\text { da velocidade } \\
\text { de condução; } \\
\text { sinais de } \\
\text { desnervação }\end{array}$ & $\begin{array}{l}\text { CT: Atrofia } \\
\text { moderada } \\
\text { córtico } \\
\text { subcortical }\end{array}$ & + & + & óbito aos $15 \mathrm{~m}$ \\
\hline 4 & $\mathbf{M} / \mathbf{1 5 m}$ & $7 \mathrm{~m}$ & $\begin{array}{l}\text { Quedas para } \\
\text { trás; deixou } \\
\text { de apanhar; } \\
\text { hipertonia; } \\
\text { surtos febris }\end{array}$ & $\begin{array}{l}\text { Segue com os olhos, } \\
\text { irritabilidade, hiper- } \\
\text { tonia, opistótono, } \\
\text { reflexos profundos } \\
\text { abolidos, Rossolimo } \\
\text { e Babinski, clono } \\
\text { dos pés, PC } 43.5 \mathrm{~cm}\end{array}$ & $\longrightarrow$ & $\begin{array}{l}102 \mathrm{mg} / \mathrm{dL} \\
\text { proteína }\end{array}$ & - & $\begin{array}{l}\text { CT: Atrofia } \\
\text { cortical } \\
\text { RNM: Des- } \\
\text { mielinização } \\
\text { difusa; realce } \\
\text { periférico }\end{array}$ & + & & Vivo \\
\hline 5 & $\mathbf{M} / 8 \mathrm{~m}$ & $5 \mathrm{~m}$ & $\begin{array}{l}\text { Diminuição } \\
\text { dos } \\
\text { movimentos; } \\
\text { apatia, choro } \\
\text { intenso; } \\
\text { espasmos }\end{array}$ & $\begin{array}{l}\text { Sem contato, irrita- } \\
\text { bilidade, hipertonia, } \\
\text { opistotono, reflexos } \\
\text { profundos abolidos } \\
\text { Rossolimo e } \\
\text { Babinski, PC } 42,5 \mathrm{~cm}\end{array}$ & $\begin{array}{l}\text { Pais primos } \\
1^{\circ} \text { grau }\end{array}$ & $\begin{array}{l}144 \mathrm{mg} / \mathrm{dL} \\
\text { proteina }\end{array}$ & $\begin{array}{l}\text { Alterações } \\
\text { compatíveis } \\
\text { a processo } \\
\text { desmielini. } \\
\text { zante }\end{array}$ & $\begin{array}{l}\text { CT: Normal } \\
\text { RNM: Des- } \\
\text { mielinização } \\
\text { difusa }\end{array}$ & + & & $\begin{array}{l}\text { obito aos } 13 \mathrm{~m} \\
\text { Autópsia: } \\
\text { leucodistrofilit } \\
\text { a células } \\
\text { globóides }\end{array}$ \\
\hline
\end{tabular}

* galoctocerebrosídeo; $\beta$-galactosidase. 


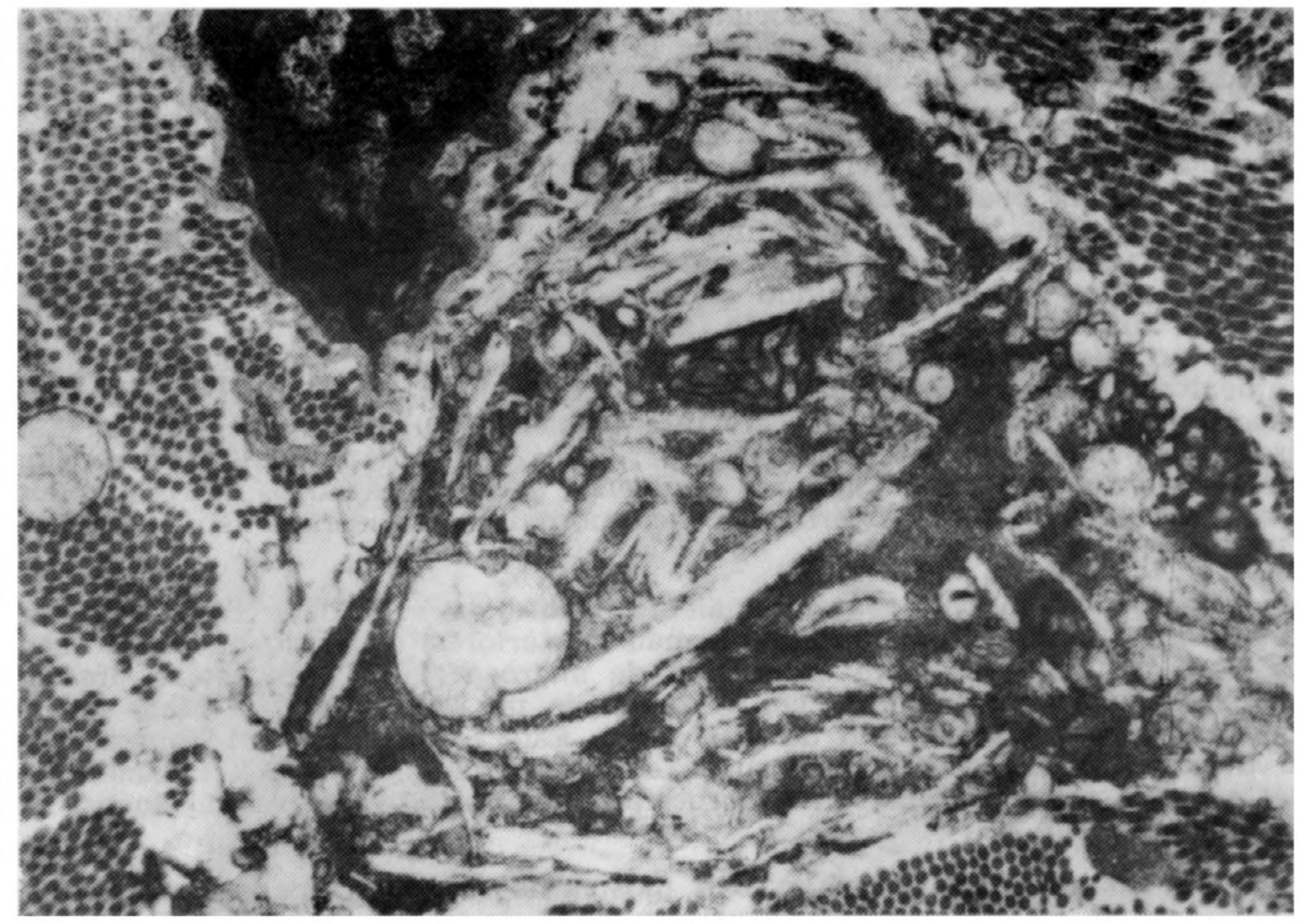

Fig. 3. Obs. 4. Aspecto ultrastrutural de nervo periférico: célula mesenquimal contendo em seu citoplasma numerosas estruturas cristaliformes. $\times 3500$.

nervoso periférico do tipo desmielinizante (velocidades de condução não obtidas). A biópsia de nervo sural revelou inclusões cristaliformes nas células de Schwann. CT do crânio revelou-se normal e a RNM mostrou alteração da substância branca, com preservação das fibras em U, caracterizada por hipo sinal em Tl e hiper sinal em T2. A criança faleceu com 16 meses de idade por broncopneumonia e a autópsia revelou leucodistrofia a células globóides.

\section{COMENTÁRIOS}

A evolução clínica, bem como os sinais e sintomas apresentados por nossos pacientes, cujos principais dados estão sumariados na Tabela 1, são característicos de doença metabólica hereditária do sistema nervoso, na forma infantil precoce, e muito sugestivos da doença de Krabbe. Nesta forma, a doença se inicia antes dos 6 meses em $80 \%$ dos casos, em $25 \%$ ocorrendo o início antes do $3^{\circ}$ mês. $O$ início após o $\mathbf{l}^{\prime}$ ano $e ́$ raro (menos que 10\%) i. De nossos 5 casos, 4 iniciaram a doença antes dos 6 meses. :É difícil individualizar exatamente quais os sinais mais precoces, pois o início é insidioso e, quando definitivamente os pais ou pediatras se dão conta que algo está errado, o quadro geralmente já está instalado. Hagberg e col. 6 dividiram a doença em três estádios: no primeiro aparecem os primeiros sinais e sintomas da doença com início de deterioração psicomotora, episódios de febre inexplicada, irritabilidade; no segundo, há nítida deterioração neurológica, hipertonia, tendência ao opistótono; e no terceiro, a fase terminal, quadro praticamente vegetativo. É difícil estabelecer qual a exata sequência dos acontecimentos. Té, certo, porém, que decadência intelectual e distúrbios motores ocorrem quase simultaneamente, sendo a primeira tanto mais notável quanto mais tardio for o início da doença: a criança passa a se desinteressar pelo meio, deixa de brincar e logo pára de apanhar objetos, pára de falar ou gorgear. A perda do controle cefálico parece ser o primeiro sinal motor e logo, se a criança já sentava com ou sem apoio, deixa de fazê-lo. A estes sinais, que são inteiramente inespecíficos, comuns à quase totalidade das doenças meta- 
bólicas infantis precoces, se associam dois outros, que se não patognomônicos, são extremamente sugestivos da doença de Krabbe: os espasmos tônicos e a irritabilidade exagerada.

Os espasmos, que podem sei espontâneos ou aparecer durante a manipulação da criança, se caracterizam por hiperextensão dos membros e da cabeça, o que leva a uma posição de opistótono. Estes espasmos, que duram de poucos segundos a alguns minutos, tendem a se repetir várias vezes por dia. Com eles, há irritabilidade e choro exagerado que podem permanecer mesmo em sua ausência, tornando-se o pano de fundo comportamental permanente da criança, que se torna difícil de ser manipulada, alimentada e cuidada. Com o tempo, ou mesmo no início, a hipertonia em extensão é permanente, interessando todos os segmentos. Os sinais de Babinski e de Rossolimo são praticamente constantes, mas os reflexos profundos são caracteristicamente hipoativos ou abolidos. Esta dissociação, consequente à neuropatía periférica associada, constitui outro sinal que, dentro do contexto, é sugestiva da doença de Krabbe. Surtos febris de causa ignorada também podem sugerir a doença, porém sua incidência não é constante (Obs. 1 e 4).

Após o início da doença, há alentecimento da velocidade de crescimento da cabeça e mesmo parada nas fases mais posteriores, de modo que quase sempre os pacientes apresentam certo grau de microencefalia. Esta estava presente em todos os nossos pacientes com exceção de um (Obs. 1), cuja idade era de apenas 4 meses no momento da internação. Este fenômeno é um bom auxiliar no diagnóstico diferencial com outras entidades que incidem na mesma faixa etária e que podem cursar com macrocefalia, com as doenças de Tay-Sachs, Alexander e Canavan.

Dos exames laboratoriais, o LCR mostra na quase totalidade dos casos aumento da taxa de proteínas, cujos valores variam de 70 a $450 \mathrm{mg} / \mathrm{dL}$. Em nossas observações, as taxas variaram de 69 a $186 \mathrm{mg} / \mathrm{dL}$. Os demais exames, em particular, gasometría, ionograma, enzimas hepáticas e pesquisa de ácidos lático e pirúvico, estão dentro dos valores normais.

O EEG é inespecífico, podendo ser normal durante longo período da evolução ou mostrar sinais de sofrimento difuso. Quatro de nossos casos foram submetidos a este exame. Em um não se observaram alterações e, nos demais, havia sinais de sofrimento difuso (ondas lentas com caráter contínuo, às vezes com ondas agudas de projeção difusa). O EMG revela, característicamente, redução importante das velocidades da condução, fato observado nos 4 casos nos quais este exame foi realizado.

A CT do crânio, sobretudo nas fases iniciais da doença, pode não mostrar alterações. Nas fases mais tardias pode mostrar moderada hipodensidade da substância branca periventricular, sem atingir os intensos graus observados em outras leucodistrofias (Obs. 2), bem como discreta dilatação ventricular e sulcos corticais proeminentes (Obs. 1, 3, 4). Em várias observações da liteuratura se descrevem hiperdensidade nos gânglios da base e tálamos e, mais raramente, na substância branca profunda, que seriam características da doença de Krabbe 3,4,9. Não encontramos estes aspectos em nenhuma de nossas 5 observações.

Poucos casos de doença de Krabbe foram submetidos à RNM 3,5,12,17, de modo que seus aspectos são insuficientemente conhecidos. Em todos os casos evidenciaram-se áreas de desmielinização em regiões periventriculares ou no centro oval, bem como atrofia cerebral. Procedemos a este exame em dois casos (Obs. 4 e 5). Em ambos, notaram-se, além de moderada atrofia difusa, alterações conspícuas da substância branca central do tipo leucodistrófico (hipo sinal em Tl e hiper sinal em T2). É digno de nota o fato de que, em ambos os casos, o exame tomográfico realizado na mesma época não havia revelado alterações, o que mostra a maior sensibilidade da RNM na detecção de lesões nesta doença. Fato idêntico foi observado no caso de Nowell e col. ${ }^{12}$. No caso em que o procedimento foi utilizado (Obs. 4), a injeção de contraste (Gadolíneo-DTPA) provocou realce particular, predominantemente na substância branca subcortical, com estriações radiadas em direção ao centro oval. A nosso conhecimento, este é o primeiro caso de doença de Krabbe no qual a técnica foi usada. É interessante notar que, tanto na forma clássica i6 como na forma tardia da doença de Krabbe $1^{3}$, 
excepcionalmente se evidenciou na TC realce justo ao lado das fibras em U, zona que constituiria a borda ativa do processo desmielinizante. Este padrão de realce, se se repetir nos futuros casos estudados, pode fazer com que a RNM se torne importante meio diagnóstico na doença de Krabbe.

A biópsia de nervo periférico é praticamente diagnostica da doença de Krabbe. Inclusões cristaliformes sem conteúdo, de contornos geométricos, em geral quadrangulares ou espiculares, bem como agregados densos de estrutura finamente lamelar são observadas no interior das células de Schwann e no citoplasma de células mesenquimais do nervo periférico ${ }^{11}$. Estas alterações estavam presentes em todas nossas observações.

Em 4 de nossas 5 observações, o diagnóstico da doença de Krabbe é absolutamente seguro, tendo sido definitivamente confirmado pelo exame neeroscópico do cérebro em duas (Obs. 1 e 5) e pela detecção do déficit enzimático em outras duas (Obs. 2 e 3 ).

Pensamos, porém, que durante a vida, mesmo na impossibilidade de se realizar o estudo enzimático, os dados anamnésicos associados aos exames clínico e laboratoriais permitem o diagnóstico de certeza da forma infantil da doença de Krabbe. Assim, diante de lactente que, dentro do primeiro ano de vida (na maioria dos casos dentro do primeiro semestre), inicia uma regressão psicomotora progressiva associada a espasmos tônicos, hipertonia global tendendo a posição em opistótono, sinais de liberação piramidal com reflexos profundos abolidos ou hipoativos, irritabilidade exagerada, surtos febris inexplicados e, mais raramente, clonias audiógenas, a hipótese da doença de Krabbe é a mais plausível. Ausência de epilepsia severa, de mioclonias espontâneas, de movimentos oculares anormais proeminentes e de amaurose precoce são importantes sinais negativos. Se, nesta criança, o exame do LCR mostrar valores aumentados de proteína e o EMG revelar diminuição significativa das velocidades de condução nervosa, o diagnóstico é praticamente certo.

Na impossibilidade de realização do exame ultrastrutural do nervo periférico e sobretudo de dosagem enzimática (não procedida em nosso meio) cremos que, baseado no quadro descrito, estará o médico autorizado a fazer o diagnóstico de doença de Krabbe, com altíssimo grau de probabilidade de acerto, e a agir em consequência, procedendo a aconselhamento genético. Quando as possibilidades o permitirem, é possível a detecção da doença em útero, pela análise enzimática de células cultivadas do líquido amniótico 8.

Agradecimentos - Os autores agradecem o Dr. François van Hoof do Service de Neurologie Pédiatrique, Hôpital St. Luc, Université Catholique de Louvain, pela realização das dosiagens enzimáticas e a Srta. Maria Eli P. de Castro pelo trabalho datilográfieo.

\section{REFERIbNCIAS}

1. Adams RD, Lyon G. Neurology of Hereditary Metabolic Diseases of Children. New York: McGraw-Hill, 1982, p 58.

2. Austin J, Lehfeldt DR, Maxwell W. Experimental globoid bodies in white matter and chemical analysis in Krabbe's disease. J Neuropath Exp Neurol 1961, 20:284-285.

3. Baram TZ, Goldman AM, Percy AX. Krabbe disease: specific MRI and CT findings. Neurotogy 1986, 36:111-115.

4. Oavanagh $\mathbf{N}$, Kendall B. High density on computed tomography in infantile Krabbe'c disease: a case report. Dev Med Child Neurol 1986, 28:799-802.

5. Demaerel PL, Wilms G, Verdru P. Carton H, Baert AL. NR findings in globoid cell leucodystrophy. Neuroradiology 1990, 32:520-522.

6. Hagberg B, Sourander P, Svennerholm L. Diagnosis of Krabbe's infantile leucodystrophy. J Neurol Neurosurg Psychiatry 1963, 26:195-198.

7. Igisu H, Susuki K. Progressive accumulation of toxic metabolite in a genetic leukodystrophy. Science 1984, 224:753-755.

8. Kudoh T, Wenger DA. Prenatal diagnosis of Krabbe disease: galactosylceramide metabolism in cultural amniotic fluid cells. J Pediat 1982, 101:754-757.

9. Kwan E, Drace J, Enzmann D. Specific CT findings in Krabbe disease. Am J Roentgenol 19\$4. 143:665-670. 
10. Loonen IvICB, Van Diggelen OP, Janse HC, Kleijer WJ, Arts WFM. Late onset globoid cell leukodystrophy (Krabbe's disease): cCinical and genetic delineation of two forms and their relation to thearly infantile form. Neuropediatrics 1985, 16:137-142.

11. Lyon G, Jardin L, Aicardi J. Etude au microscope électronique d'un nerf périphérique dans un cas de leucodystrophie de Krabbe. J Neurol Sei 1971, 12:263-274.

12. Nowell MA, Grossman RI, Hackney DB, Zimmerman RA, Goldberg HI, Bilaniuk LT. MR imaging of white matter disease in children. Am J Roentgnol 1988, 151:359-365.

13. Phelps M, Aicardi J, Vanier MT. Late onset Krabbe's leukodystrophy: a report of four cases, J Neurol Neurosurg Psychiatr 1991, 54:292-296.

14. Suzuki K, Susuki Y. Globoid cell leukodystrophy (Krabbe's disease) : deficiency of galacto-cerebroside-galactosidase. Proc Natl Acad Sei USA 1970, 66:302-309.

15. Susuki Y, Susuki K. Krabbe's globoid cell leukodystrophy: deficiency of galactocerebrosidadase in serum, leukocytes, and fibrolasts. Science 1971, 171:73-75.

16. Valk JL, Van Der Knaap MS. Magnetic resonance of myelin, myelination, and! myelin disorders. Berlin: Springer-Verlag. 1989, p 80.

17. Winants D, Bernard C, Galloy MA, Hoeffel JC, Vidailhet M. Scanographie et IRM de la maladie de Krabbe. J Radiol 1988, 69:697-700. 